\title{
Research on Fault Prognostics and Health Management Of The On-Board Equipment Of CTCS-3 Train Control System
}

\author{
Xuejie Jiang ${ }^{1}$ and Guoning $\mathrm{Li}^{2}$ \\ ${ }^{1}$ College of Automation \& Electrical Engineering, Lanzhou Jiaotong University, \\ Lanzhou, 730070, china, \\ ${ }^{2}$ College of Automation \& Electrical Engineering, Lanzhou Jiaotong University, \\ Lanzhou, 730070, china, \\ ${ }^{1} 15117010482 @ 163 . c o m$ \\ 2372514424@qq.com
}

\begin{abstract}
At present, high-speed railway is faster and faster, which puts forward higher safety requirements for high-speed railway, and the on-board equipment for CTCS-3 train control system is vital. Therefore, it is necessary to carry out real-time monitoring of the various parts of the on-board equipment in order to find the fault, isolate the fault and eliminate the fault and improve the safety of high-speed train. this paper presents the on-board equipment Prognostics and health management (PHM) research, the use of intelligent diagnosis algorithm and prediction techniques, according to the health assessment of residual life prediction and the on-board equipment for train control system state maintenance and condition based maintenance (CBM) provide a theoretical basis. Taking the GSM-R receiving station of the train control system as an example, it is concluded that the scoring standard and health index (HI) are more reliable for fault prediction and health management.
\end{abstract}

Keywords: The on-board equipment for train control system ; Prognostics and health management; Health index; Residual life

\section{Introduction}

CTCS-3 Train Control System ${ }^{[1,2]}$ is composed of the ground railway signal equipment and the on-board equipment high security system, is the ground of computer interlocking equipment extending to the on-board equipment. On the basis of this security realized based on on-board equipment driving method. All the countries in the world in the process of implementation of the train operation control, fault oriented security as important technical condition, the on-board equipment and ground signal equipment according to a standard unified $\mathrm{R} \& \mathrm{D}$ design, synchronous update manufacturing to ensure train operation control system of high security, high reliability. On-board equipment of train control system is an important part, literature [3] the train control on-board equipment reliability assessment, Bayesian network respectively analysis system maintainability, a total of cause failure and multiple failure modes and the degraded mode were reliability evaluation. literature [4] the train control on-board equipment system key equipment simulation research, literature [5] the large aircraft airborne systems are equipped with advanced prognostics and health management (PHM) system is presented, and the airplane fault prognosis and health management and health management of adaptability analysis.

Now the development of high-speed railway in the world, the continuous improvement of the speed of high-speed railway, ground equipment gradually cancel, the on-board equipment safety proposed higher requirements, which requires

* Xuejie Jiang Telephone:15117010482 E-mail:15117010482@163.com.

The controller design of a multi - under - driven mechanical system based on controlled Lagrange function in the national natural foundation area project (61164010).

ISSN: 1738-9976 IJSIA

Copyright (C) 2016 SERSC 
monitoring Fault Prognostics and health management of on-board equipment, in order to improve the reliability and safety, effectively protect high-speed train driving safety and the people's life and property safety.

This paper based on support vector machine (SVM) and multi sensor information fusion intelligent diagnosis algorithm and the theory of reliability analysis ${ }^{[6]}$, the introduction of train control on-board equipment, the average remaining life concept, the equipment for residual life assessment, according to the on-board equipment residual life dynamic adjustment of maintenance interval time and improve reliability and safety. Because the support vector machine has a good learning and generalization ability for small sample analysis and decision, it uses the support vector machine and multi sensor information fusion intelligent algorithm for fault diagnosis of on-board equipment.

\section{System Structure of CTCS-3 On-Board Equipment PHM System}

The realization of the train control PHM system mainly depends on the system partition, the mutual constraint management, the use of the system structure mode and the system structure integration strategy. The train control PHM system is a system which has the information management and the logistics security management. It is a portable, can cooperate the open system. Often take based on IEEE1471-2000 (Recommended Practice for software intensive system architecture description) and ISO13374 open system architecture for condition based maintenance (OSA-CBM) and SIL4 European safety standard and standard construction of train control system of PHM system, according to the above international standards for the construction of the train control PHM system as shown in Figure 1.

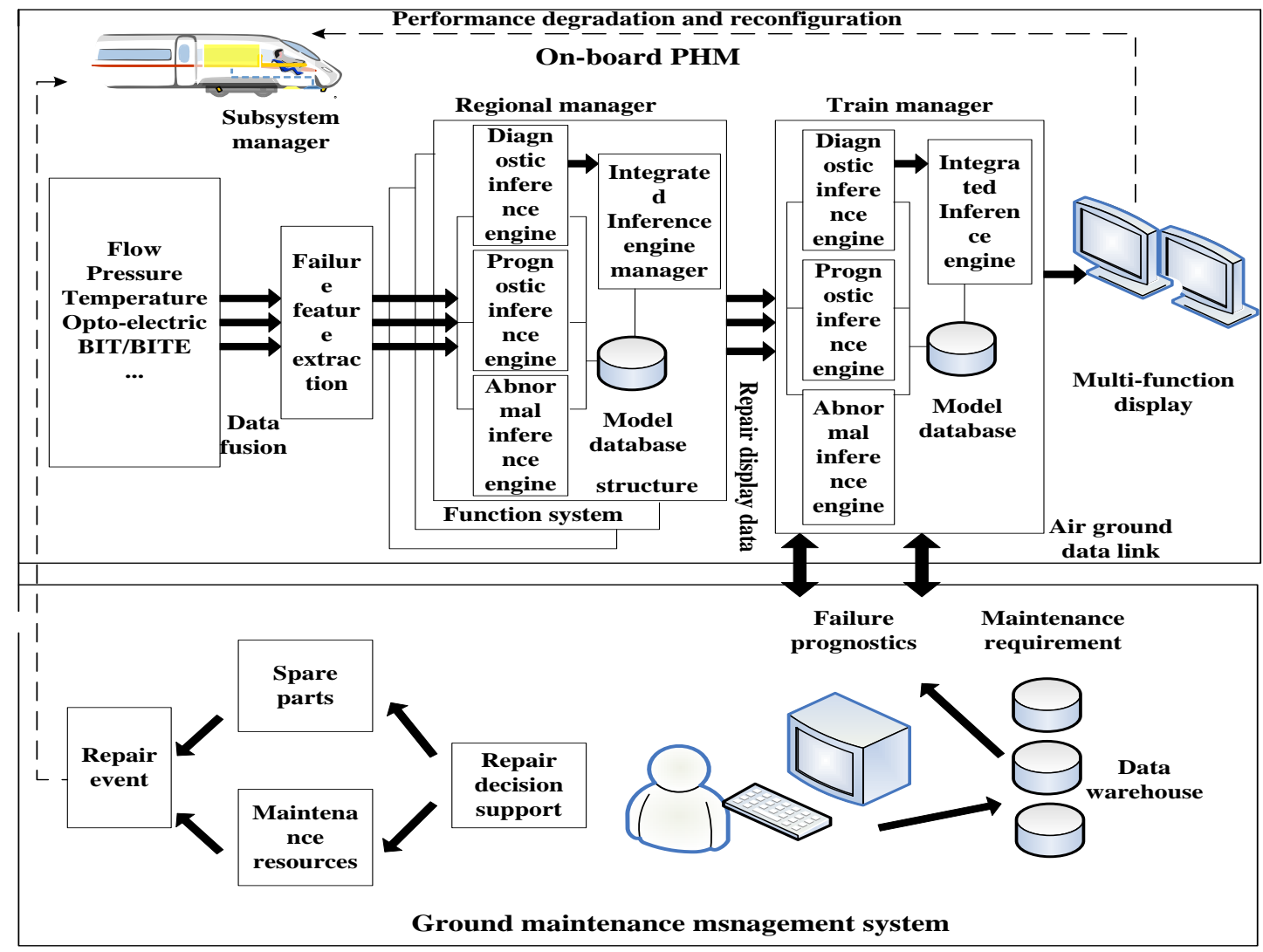

Figure 1. Structure of Train Fault Prognostics and Health Management (PHM) System 
The system has the following characteristics: (1)The system has the characteristics of hierarchical structure, distributed and open style; (2) it has the module structure and standard interface specification; (3) and the prediction, diagnosis and maintenance decision of the system is real-time. The architecture can provide an open environment for diagnosis and prediction, which can be integrated with many kinds of reasoning algorithms, and can be easily and quickly integrated with the main operating environment to achieve high efficiency and real-time operation. PHM system in the most secure way to deal with emergencies, the real-time monitoring of the health status of each on-board equipment, predict the remaining life, improve the reliability and safety of train operation, and reduce the cost of maintenance.

From Figure 1, we can see that the train PHM system architecture mainly consists of three parts: the vehicle PHM system, the vehicle ground communication system and the ground maintenance management system. The vehicle PHM system is mainly to complete the real-time monitoring and prediction of the health status of each equipment, diagnosis and abnormal reasoning. In order to improve the accuracy of fault diagnosis and reasoning, Train PHM system is based on the data flow of the three layer structure planning: the related distribution sensor and feature extraction of the subsystem managers; on-board equipment prediction, diagnosis and abnormal reasoning regional manager; and operation of the train manager control.

The train PHM were analyzed according to the on-board equipment failure law, set up a number of sensors in the key information detection, multi sensor information collected by signal processing to extract fault features, the inference engine to extract data input to the assistant manager, reasoning and reasoning machine adopts advanced data fusion technology. Performance, health and maintenance, fault and residual life state monitoring results of various devices, which adopt fault feature extraction technique based on robust fault section, fault diagnosis adopt support vector machine (SVM) and multi sensor information fusion intelligent diagnosis algorithm, by improving the positioning in fault diagnosis accuracy of hierarchical clustering technology. Assistant manager according to the obtained information fusion by abnormalities, faults and predict the inference engine reasoning and transmit the results to the main management analysis and decision-making, if a fault occurs the system follow guided fault safety principle of processing, and timely isolation fault security, in arriving at the station for maintenance and fault information is transmitted to the ground maintenance management system, to ensure that the safe operation of the train, and improve the service quality and efficiency.

According to the PHM and to predict the residual life estimation of on-board equipment, draw the health status of equipment, the first pre detection and maintenance, to eliminate the possibility of failure in time, ensure traffic safety.

\section{Hierarchical Intelligent Reasoning Diagnosis of CTCS-3 On-board equipment PHM}

\subsection{Hierarchical Intelligent Reasoning}

The traditional fault diagnosis reasoning using only a criterion often appear error in judgment, and train PHM the hierarchical intelligent reasoning mechanism as shown in Figure 2, by inference layer judgment and comprehensive analysis, the conclusion shows that the hierarchical reasoning, greatly improves the accuracy of fault diagnosis, thereby reducing the probability of misjudge. 


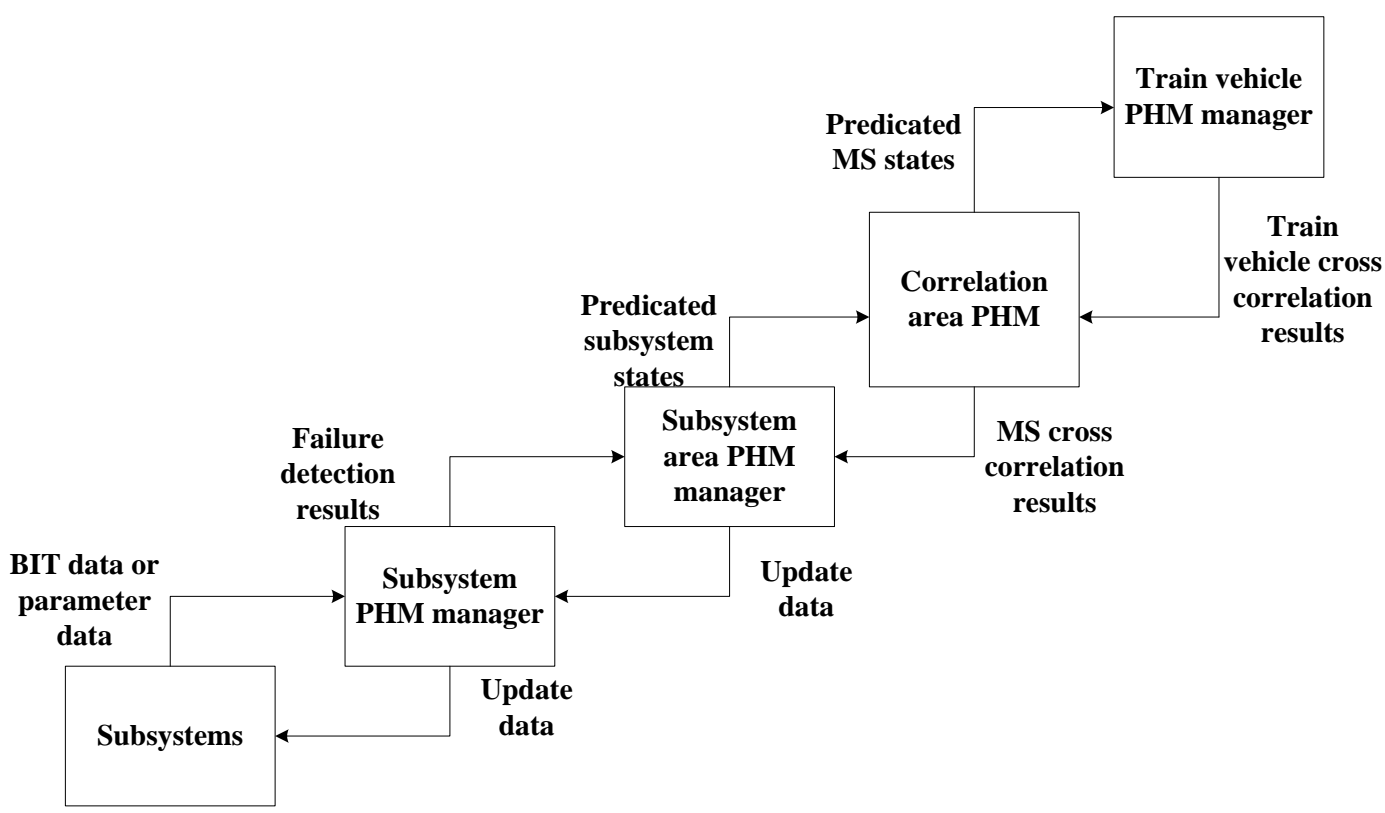

Figure 2. Hierarchy Structure of Train PHM System

According to the locomotive PHM system structure, PHM divided subsystem level, regional manager level and train manager three layer structure, subsystem level contains the BITE data, acquisition parameters, subsystem of fault diagnosis and management; regional manager in addition to the fault diagnosis and prediction and calibration function. Each layer of reasoning between the use of different data, each layer of only the management of the event, the layer and layer to check each other, in order to improve the safety of locomotive health management.

Because the locomotive PHM contains the switch control signal, continuous information signal and equipment performance status information, so this paper designed three types of reasoning machine:

(1) Predictive inference engine is used to determine the on-board equipment performance degradation law, according to the health status of detection equipment, and calculation of residual life estimated possible fault types and fault time zone, and to the ground maintenance management system to send information, and maintenance of security.

(2) Diagnosis reasoning machine to detect the continuous change signal, design support vector machine (SVM) intelligent diagnosis algorithm, accurately determine the fault location, inform the relevant personnel to deal with the fault and isolate the fault source.

(3) Abnormal fault machine on the switch signal or slow change continuous signal design fixed threshold, if the signal processing is more than the fixed threshold value is regarded as abnormal state, immediately inform the alarm and timely view processing.

\subsection{Intelligent Fault Diagnosis Algorithm}

(1) Support vector machine (SVM) fault diagnosis

Support vector machine (SVM) is established on the basis of structural risk minimization, is the pursuit of intelligent methods in finite samples under the optimal solution, and not in the samples to infinity when the optimal solution. It is especially suited for fault diagnosis. Application of SVM in fault diagnosis is actually a classification problem, it according to the detection of locomotive running all kinds of data information (such as performance parameters, vibration frequency, waveform 
characteristics), classification judgment whether there is fault, find the position and cause of the on-board equipment fault. The SVM can achieve the classification result in the training sample is very small and does not know the prior knowledge in advance, moreover the generalization ability is stronger. As shown in Figure 3, in the figure, $M_{1}, M_{2}, M_{3}$, respectively, for the three fault zones; $\omega_{1} 、 \omega_{2} 、 \omega_{3}$,espectively, the $M_{1}, M_{2}$, $\mathrm{M}_{3}$ region of the weight.

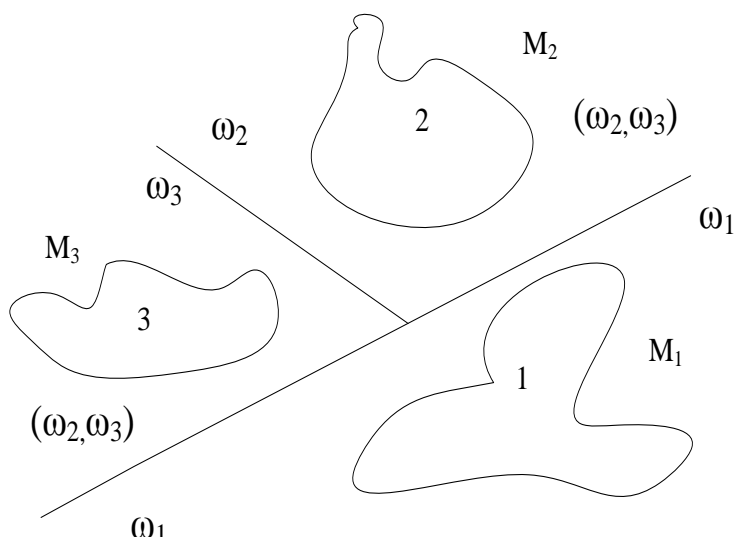

Figure 3. Fault Classification Based On Support Vector Machine (SVM)

(2)Multi sensor information fusion fault diagnosis

Information fusion is a kind of intelligent synthesis of various types of information, which is more accurate and complete estimation and decision method than single information. Multi sensor information fusion method based on the weight coefficient of the fusion method, based on D-S theory of reasoning fusion method, based on Kalman filtering fusion method, based on fuzzy neural network fusion method and based on rough set theory fusion method ${ }^{[7]}$, its application field is quite wide. PHM uses the hybrid fusion method as shown in Figure 4

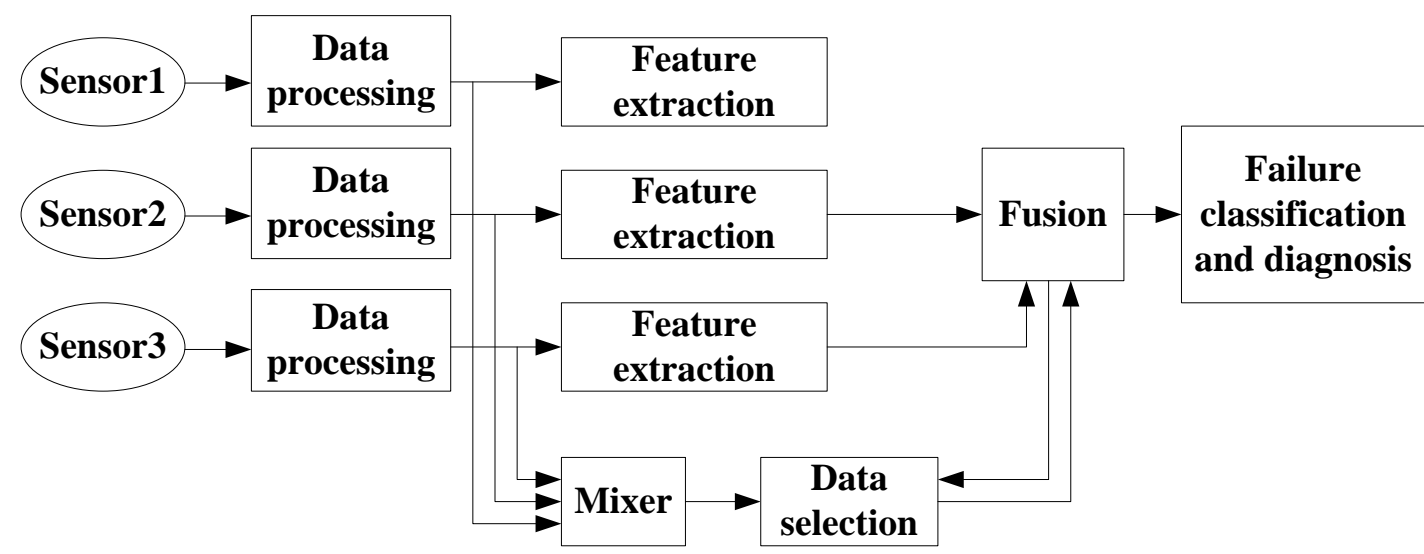

Figure 4. Data Fusion Fault Diagnosis Based on Multiple Sensors

In Figure 4, the data of sensor detection and the characteristic vector data can be processed simultaneously, in the process of data fusion can according to need to extract valuable information from sensor data to improve the intelligent algorithm of calculating speed and accuracy. In order to prevent mutual interference and other 
independent fault classification methods to deal with the characteristic vector signals, the fault isolation is achieved.

\section{PHM Fault Prediction Technology of CTCS-3 On-Board Equipment}

\subsection{Fault Prediction of Remaining Life of On-Board Equipment Based on Train Control}

The distribution of each of the service life of the equipment is not the same, but each kind of equipment life distribution is a reflection of the failure mechanism of this type of equipment, so life distribution can reflect the essence of the state of equipment failure. The common life of equipment distribution is Poisson distribution, Weibull distribution, normal distribution, exponential distribution and lognormal distribution. CTCS-3 on-board equipment by use of electronic equipment, so on-board equipment life distribution with two parameter Weibull distribution model.

\subsubsection{Weibull Distribution Test}

In recent years in the theory of reliability analysis is a widely used is Weibull distribution, and through a large number of experimental results show that, because of the life of a local failure or malfunction caused by all the properties to stop running components, devices, equipment, systems service from the Weibull distribution and Weibull distribution commonly used to describe the aging, wear, fatigue failure of the phenomenon of equipment life distribution ${ }^{[8,9]}$.

This paper uses two parameter Weibull distribution, the reliability of distribution function is

$$
R(t)=\exp \left[-\left(\frac{t}{\eta}\right)^{\beta}\right] \quad t \geq 0
$$

Loss of efficiency function is

$$
\lambda(t)=\frac{\beta}{\eta}\left(\frac{t}{\eta}\right)^{\beta-1} \quad t \geq 0
$$

Fault density function is

$$
f(t)=\frac{\beta}{\eta}\left(\frac{t}{\eta}\right)^{\beta-1} \exp \left[-\left(\frac{t}{\eta}\right)^{\beta}\right] \quad t \geq 0
$$

In the type, $\beta$ is the Shape parameter; $\eta$ is the scale parameter. When $\beta>1$, the failure rate is increasing progressively trend, suitable for wear and aging equipment failure for a class of late; when $0<\beta<1$, the failure rate is a decreasing trend; suitable for equipment of early failure; when $\beta=1$,it is the exponential distribution, the failure rate is constant for random failure of the equipment.

On-board equipment life data is in line with the Weibull distribution test for collect a set of CTCS-3 Train Control, first on the reliability function on both sides of take the $\log$ twice get

$$
\ln (-\ln (R(t)))=\beta \ln t-\beta \ln \eta
$$

Subsequent plotting $\ln t$ and $\ln (-\ln (R(t)))$ as a function curve, if the sample data obeys Weibull distribution, then drawing curve should fit for a slope greater than 0 linear, the slope of the line is the Weibull distribution estimation value of shape 
parameter [10].

\subsubsection{Prediction of Life and Remaining Life}

In Figure 5, the P-F curve describes a process from a healthy state to a complete failure of the device, is actually a process of complete failure by latent fault to function. So-called latent fault is to say there is no failure, but there are some signs that failure may be will happen, that is to say there are hidden faults ${ }^{[12]}$; a complete failure function is generally refers to the mechanical fault, is a total failure of the equipment. Figure $\mathrm{P}$ is the weak can point to the detection of latent fault, $\mathrm{F}$ point for functional failure point, $\mathrm{T}$ is the time interval between the latent fault point and the functional failure point, and $\mathrm{T}_{1}$ is the time interval for preventive maintenance testing.

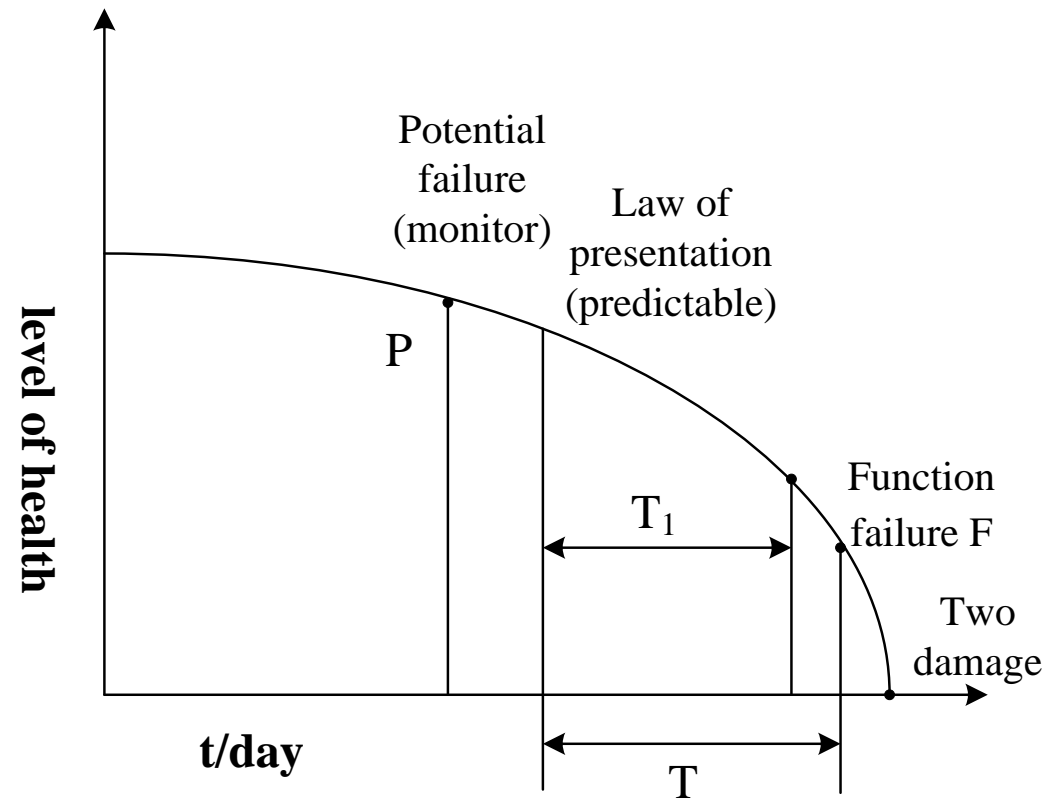

Figure 5. P-F Curve

In the actual operation of the train control system, the on-board equipment of train by the system real-time monitoring and maintenance personnel on a regular basis to detect, get the current running state of the equipment, if all the normal operation of the equipment, that is in good condition, based on the running time t can get a conditional residual life

$$
T_{t}=T-t
$$

$$
T>t
$$

\subsubsection{Average Life Expectancy}

Average life expectancy of equipment is the mean time before failure, which is the expected value of $\mathrm{T}$, as shown in the formula

$$
E(T)=\int_{0}^{\infty} R(t) d_{t}
$$

As for train control on-board equipment life distribution obeys two parameter Weibull distribution, (1) inserting (6) get the average life expectancy 


$$
E(T)=\eta \int_{0}^{\infty} x^{\frac{1}{\beta}} e^{-x} d_{x}
$$

\subsubsection{Average Residual Life Prediction}

The reliability function of residual life $T_{t}$

$$
\begin{aligned}
& R_{t}(u)=P\left(T_{t} \geq u\right)=P((T-t \geq u) \mid T \geq t) \\
& =\frac{R(t+u)}{R(t)} \quad u \geq 0
\end{aligned}
$$

(8) inserting (6) get the residual life of $T_{t}$ type expected value

$$
E\left(T_{t}\right)=\int_{0}^{\infty} R_{t}(u) d_{u}=\frac{1}{R(t)} \int_{0}^{\infty} R(u) d_{u}
$$

In the formula (9), which is the formula for calculating the average residual life, is represented by $\mu(\mathrm{t})$. Therefore, the probability density function of remaining life at $\mathrm{t}$ time is

$$
\begin{aligned}
& f_{t}(u)=\frac{1}{R(t)} \frac{d R(t+u)}{d_{u}}= \\
& -\exp \frac{d\left[\exp \left(-\left(\frac{t+u)}{\eta}\right)^{\beta}\right)\right]}{d_{u}}= \\
& \left(\frac{\beta}{\eta}\right)\left(\frac{t+u}{\eta}\right)^{\beta} \exp \left[\left(\frac{t}{\eta}\right)^{\beta}-\left(\frac{t+u}{\eta}\right)^{\beta}\right] \\
& u \geq 0
\end{aligned}
$$

The average residual life is the mathematical expectation value of residual life probability distribution, therefore, the train control on-board equipment life obey Weibull distribution, by equation (10) get the mean residual life calculation formula is

$$
\begin{aligned}
& \mu(t)=E\left(T_{t}\right)=\frac{1}{R(t)} \int_{0}^{\infty} R(u) d_{u}= \\
& \frac{1}{\exp \left[-\left(\frac{t}{\eta}\right)^{\beta}\right]^{\infty}} \int_{0}^{\infty} \exp \left[-\left(\frac{u}{\eta}\right)^{\beta}\right] d_{u}
\end{aligned}
$$

To get the CTCS-3 on-board equipment service life is the time t plus the mean residual life of the $t$ time predicted, learned that the life data of the on-board equipment, so the on-board equipment health management to adjust maintenance to improve the reliability and safety.

\subsection{Fault Prediction Technology Based on Data}

Real-time data is valuable information about the train, so data based fault prediction can be more real close to the actual system operation, and more real understanding of the train operation system of the state, resulting in a more realistic predictions. The 
technical difficulty lies in the obtained by historical data prediction model can be applied to the field and its generalization ability, only the most reasonable application can achieve accurate prediction in the future. Therefore, it is very difficult to have a unified prediction method, here is a commonly used prediction method as shown in Figure 6.

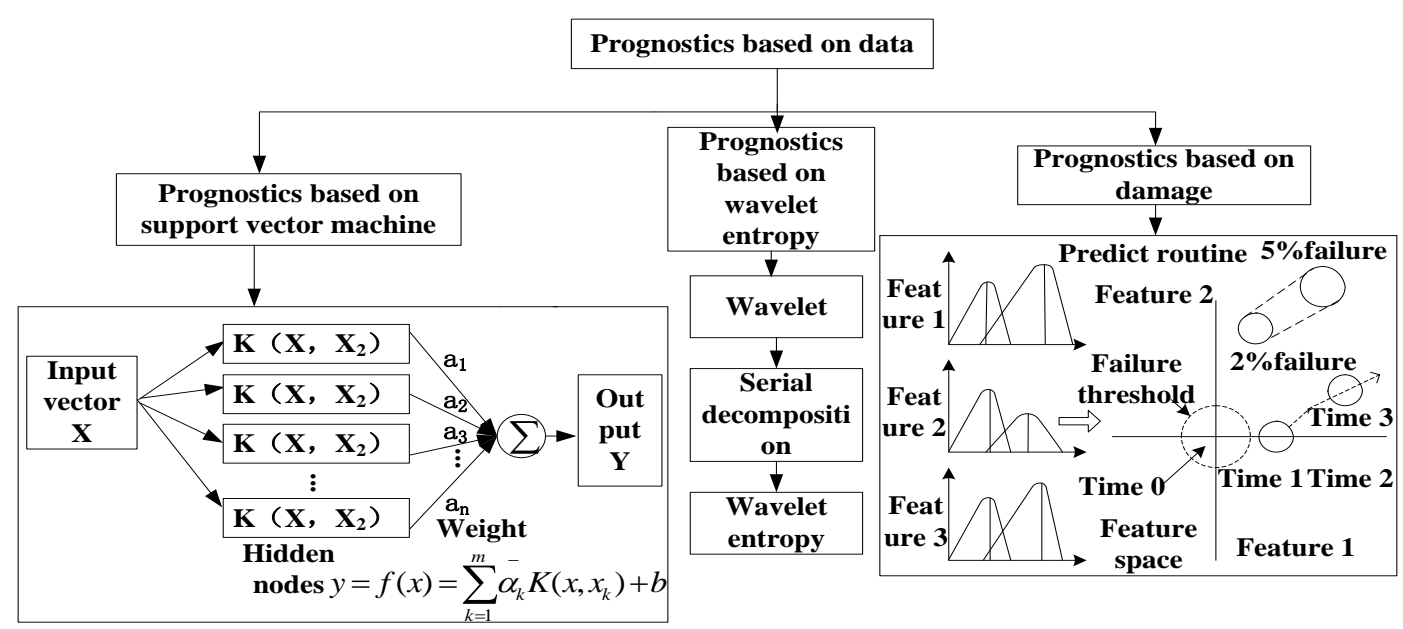

Figure 6. Fault Prognostics Based on Data

In Figure 6, the multiple scale support vector machine is used to decompose the collected stable and unstable signals, one by one analysis, in the synthesis of the final results forecast ${ }^{[13]}$. Based on wavelet energy entropy of fault prediction technology, the signal after wavelet packet transform, the calculation of wavelet energy entropy for fault prediction technology ${ }^{[14]}$. Due to the many uncertainties of the data detected by multi sensors, for example, the material characteristics, pulse changes, when the sensor and the model of the response of the prediction is not consistent, then the analysis of these errors will be able to sort out the fault prediction.

\section{CTCS-3 on-Board Equipment Health State Evaluation Grade}

Due to the effects of train control on-board equipment of many factors such as length of operation time, operation environment is good or bad, maintenance technical parameters, operation, and so on can, have an important influence on on-board equipment safety, so the use of based on fuzzy comprehensive evaluation ${ }^{[15]}$ train control on-board equipment health status, the train control equipment to quantify and quantitative results define for train control on-board equipment health index (HI). HI indicators for the health status of train control on-board equipment, HI value between $0 \sim 100$, divided into four levels: health, sub-health, abnormal and fault. HI is close to 100 indicating the equipment more healthy, 60 is set to the critical value of HI, while less than 60 is considered to be a failure, is greater than 60 for normal, healthy state of on-board equipment level and the qualitative description as shown in Table 1. 
Table 1. CTCS-3 Train Control System on the Health Status of On-Board Equipment

\begin{tabular}{|c|c|c|l|l|}
\hline level & $\begin{array}{c}\text { HI value } \\
\text { range }\end{array}$ & Health level & \multicolumn{1}{|c|}{ Security description } & \multicolumn{1}{|c|}{ Risk description } \\
\hline 1 & $85 \leq \mathrm{HI} \leq 100$ & health & $\begin{array}{l}\text { The status parameter is rated, } \\
\text { and the equipment is safe. }\end{array}$ & $\begin{array}{l}\text { The possibility of } \\
\text { failure is very small }\end{array}$ \\
\hline 2 & $70 \leq \mathrm{HI} \leq 85$ & sub-health & $\begin{array}{l}\text { Status parameter is not in the } \\
\text { range of rated value, } \\
\text { equipment is not safe, } \\
\text { strengthen monitoring }\end{array}$ & $\begin{array}{l}\text { The possibility of } \\
\text { failure can be dealt } \\
\text { with within the scope } \\
\text { of }\end{array}$ \\
\hline 3 & $60 \leq \mathrm{HI} \leq 70$ & abnormal & $\begin{array}{l}\text { Status parameter is greatly } \\
\text { deviated from the rating, } \\
\text { equipment is not safe, } \\
\text { strengthen monitoring and } \\
\text { isolation }\end{array}$ & $\begin{array}{l}\text { The possibility of } \\
\text { failure, the need to } \\
\text { check and repair as } \\
\text { soon as possible }\end{array}$ \\
\hline 4 & $0 \leq \mathrm{HI} \leq 60$ & fault & $\begin{array}{l}\text { Equipment failure, isolation, } \\
\text { must be overhaul }\end{array}$ & $\begin{array}{l}\text { Must be checked and } \\
\text { repaired immediately. }\end{array}$ \\
\hline
\end{tabular}

Table 2. Rating Criteria

\begin{tabular}{|c|c|c|}
\hline \multirow{4}{*}{$\begin{array}{l}\text { Maintenance } \\
\text { record }\end{array}$} & $\begin{array}{l}\text { From the last time the maintenance of the } \\
\text { repair cycle is not more than } 1 / 4\end{array}$ & 90 points or more \\
\hline & $\begin{array}{l}\text { From the last time the maintenance of the repair } \\
\text { cycle is not more than } 1 / 2\end{array}$ & 75 90 points \\
\hline & $\begin{array}{l}\text { From the last time the maintenance of the repair } \\
\text { cycle is not more than } 3 / 4\end{array}$ & $60 \sim 75$ points \\
\hline & $\begin{array}{l}\text { From the last time the maintenance of the repair } \\
\text { cycle is more than } 3 / 4\end{array}$ & under 60 points \\
\hline \multirow{4}{*}{$\begin{array}{l}\text { technical } \\
\text { parameter }\end{array}$} & excellent & 90 points or more \\
\hline & good & 75 90 points \\
\hline & middle & $60 \sim 75$ points \\
\hline & bad & under 60 points \\
\hline \multirow{4}{*}{$\begin{array}{l}\text { Operating } \\
\text { environment }\end{array}$} & Better to meet the working environment & 90 points or more \\
\hline & Good to meet the working environment & $75 \sim 90$ points \\
\hline & Basically meet the working environment & $60 \sim 75$ points \\
\hline & Do not meet the working environment & under 60 points \\
\hline \multirow{4}{*}{$\begin{array}{l}\text { Family quality } \\
\text { history }\end{array}$} & Excellent & 90 points or more \\
\hline & Good & $75 \sim 90$ points \\
\hline & Middle & $60 \sim 75$ points \\
\hline & $\mathrm{Bad}$ & under 60 points \\
\hline \multirow{4}{*}{$\begin{array}{c}\text { Actual } \\
\text { operating } \\
\text { condition }\end{array}$} & Excellent & 90 points or more \\
\hline & Good & 75 90 points \\
\hline & Middle & $60 \sim 75$ points \\
\hline & bad & under 60 points \\
\hline
\end{tabular}

According to the fuzzy comprehensive evaluation rules of train control on-board equipment of the health status of qualitative score to represent the device health state, qualitative rating criteria such as Table 2 shows, therefore, health management, condition based maintenance (CBM) that to save costs, and ensure the security.

On the station using 5 years of train control system GSM-R receiving station as an example of health analysis and life prediction, the rationality and validity of this paper 
is verified. The quantitative indexes of the on-board equipment are reduced by half trapezoid function as shown in the formula (12)

$$
X= \begin{cases}1 & X \leq a_{1} \\ \frac{a_{2}-X}{a_{2}-a_{1}} & a_{1}<X \leq a_{2} \\ 0 & X>a_{2}\end{cases}
$$

In the formula: $a_{1}, a_{2}$, respectively, which indicated that index of optimal value and life value, the optimal value for operating years for equipment investment before running out of time, that time is running out for 0 years; life value for equipment factory specified rated operating years. Time now GSM-R receiving station for 20 years, into the formula (12) $\mathrm{X}=0.31$. The quantitative index score is divided into 60 , and the running time is converted to the index score

$x=60+60 \times 69 \%=81.3$

So the index score can be drawn as follows: Table 3

Table 3. Index Score

\begin{tabular}{|c|c|c|c|}
\hline Evaluation index & score & Evaluation index & score \\
\hline $\begin{array}{c}\text { Maintenance } \\
\text { record }\end{array}$ & 94 & $\begin{array}{c}\text { Actual operating } \\
\text { condition }\end{array}$ & 92 \\
\hline $\begin{array}{c}\text { Technical } \\
\text { parameter }\end{array}$ & 90 & $\begin{array}{c}\text { Family quality } \\
\text { history }\end{array}$ & 83 \\
\hline $\begin{array}{c}\text { Operating } \\
\text { environment }\end{array}$ & 88 & Run time / year & 81 \\
\hline
\end{tabular}

Table 4. Index Weight

\begin{tabular}{|c|c|c|c|}
\hline Evaluation index & Weight & Evaluation index & Weight \\
\hline $\begin{array}{c}\text { Maintenance } \\
\text { record }\end{array}$ & 0.284 & $\begin{array}{c}\text { Actual operating } \\
\text { condition }\end{array}$ & 0.015 \\
\hline $\begin{array}{c}\text { Technical } \\
\text { parameter }\end{array}$ & 0.135 & $\begin{array}{c}\text { Family quality } \\
\text { history }\end{array}$ & 0.352 \\
\hline $\begin{array}{c}\text { Operating } \\
\text { environment }\end{array}$ & 0.120 & Run time / year & 0.090 \\
\hline
\end{tabular}

Table 4 layered index weight calculation and analysis, according to Table 3 index score and Table 4 index weight get the health index of the on-board equipment for receiving station

$$
\begin{aligned}
& H I=94 \times 0.284+90 \times 0.135+88 \times 0.120 \\
& +92 \times 0.015+83 \times 0.352+81 \times 0.09=87
\end{aligned}
$$

So the health index HI receiving station 87 , calculated the health index over the years as shown in Table 5 in the same way.

An example shows that the health index derived from the data has a high reference value, which provides an important theoretical support for health management , and 
improve the safety and reliability of the train control system.

Table 5. Health Index of Receiving Radio over the Years

\begin{tabular}{|c|c|c|c|}
\hline Service life & HI & Service life & HI \\
\hline 1 & 99 & 6 & 82 \\
\hline 2 & 98 & 7 & 82 \\
\hline 3 & 90 & 8 & 79 \\
\hline 4 & 88 & 9 & 76 \\
\hline 5 & 87 & 10 & 75 \\
\hline
\end{tabular}

\section{Conclusion}

According to the intelligent reasoning, in the calculation of the residual life and prediction based on data and technology, provides theoretical support for the fault prediction of CTCS-3 on-board equipment, Intelligent diagnosis of train control equipment based on support vector machine classification and multi sensor information fusion, using GSM-R receiver of the CTCS-3 on-board equipment as an example, establish health index (HI) grading and scoring criteria by using the index weight and index score of the radio station, get the health index of receiving radio over the years, fault prediction and health management (PHM) of CTCS-3 on-board equipment are fully realized, not only saves the maintenance cost, and improves the reliability and safety of the train control system, provide important theoretical basis for the reliability analysis of railway equipment.

\section{References}

[1] HUANG Weizhong, JI Xuesheng, LIU Ling, LI Kaicheng, NIU Daoheng. "Several Crucial Techniques for the High Speed Adaptability of CTCS-3 Train Control On-board Equipment.", China Railway Science, vol.31,no.3,(2010),pp. 87-92.

[2] ZHANG Shuguang. "Overall technical scheme of CTCS-3 level train control system", China Railway Publishing House ,Bei Jing,(2008).

[3] SU Hongsheng,CHE Yulong,Zhang Youpeng. "Dependability Assessment of CTCS-3 On-Board Subsystem Based On Bayesian Network", China Railway Science, vol.35,no.5,(2014),pp. 96-104.

[4] XU Li,ZHANG Yong. "Design and implementation of on-board Equipment Simulation Subsystem of CTCS-3",Railway Computer Application, vol.17,no.5,(2008),pp. 8-11.

[5] WANG Shaoping. "Prognostics and Health Management Key Technology Of Aircraft Airborne System", Acta Aeronautica et Astronautica Sinica, vol.35,no.6,(2014),pp. 1459-1472.

[6] ZHANG Youpeng. "Application of reliability theory and Engineering Technology", Lanzhou University Press,Lan Zhou,(2003).

[7] Xiong N, Svensson P. "Multi-sensor management for information fusion : issues and approaches", Information Fusion, vol.3,no.2,(2002),pp. 163-186.

[8] GAO Lihua,GUO Jianying. "Estimation of based on Weibull distribution of metalized capacitor life data analysis and parameter", Silicon Valley Electronic Science, vol.23,no.8,(2009),pp. 16-18.

[9] FEI Heliang,WANG Lingling, "Product life analysis method", National Defence Industry Press,Bei Jing,(1988).

[10] RONG Xiang. " Methods of Life Prediction and Maintenance Decision Making in Civil Aeroengine Health Management”, Nanjing University of Aeronautics and Astronautics,Nan Jing,(2008),pp.49-50.

[11] MENG Xiaohong,ZHOU Yongtao,WANG Wei. " Research on equipment remaining life prediction model based on exponential distribution”, China Shiprepair, vol.25,no.5,(2012),pp. 42-44.

[12] PENG Bo,JIN Xing,YANG Yang. "Research On Optimization Maintenance Method Of Latent Fault Based On Residual Life”.Acta Armamentarit, vol.33,no.4,(2012),pp. 483-487.

[13] Yang Z, Guo J, Xu W. "Multi-scale support vector machine for regression estimation",Lecture Notes In Computer Science,vol.3971,(2006),pp. 1030-1037.

[14] GU Wenting. "Equipment Health Condition Monitoring Technology Using Entropy". Chang'an University, Xi'an,(2014),pp.23-52.

[15] LI X, LIU B D. "Chance Measure for Hybrid Event with Fuzziness and Randomness".Soft Computing,vol.13,no.2,(2012),pp. 105-115. 